incidence of breast feeding in all social classes today, however, it would surely be wrong to abandon the use of breast milk, with all its advantages, ${ }^{46}$ for a cows' milk formula for low birthweight infants on the mistaken premise that adequate growth cannot be achieved with the former.

We thank the sisters and nurses on special care baby unit for the accurate record keeping which made this study possible.

\section{References}

${ }^{1}$ French TJ, Colbeck M, Burman D, Spiedel BD, Hendey RA. A modified cows' milk formula suitable for low birthweight infants. Arch Dis Child 1982;57:507-10.

2 Valman HB, Heath CD, Brown RJK. Continuous intragastric milk feeds in infants of low birthweights. Br Med J 1972;iii: $547-50$.
${ }^{3}$ Davies DP. Adequacy of expressed breast milk for early growth of preterm infants. Arch Dis Child 1977;52:296-301.

${ }^{4}$ American Academy of Pediatrics: Committee on Nutrition. Nutritional needs of low birthweight infants. Pediatrics 1977;60:519-30.

5 Hanmer OJ, Houlsby WT, Thom H, Ross IS, Lloyd DJ, Russell G. Fat as an energy supplement for preterm infants. Arch Dis Child 1982;57:503-6.

${ }^{6}$ Narayanan I, Prakesh K, Guzral VV. The value of human milk in the prevention of infection in the low birthweight infant. $J$ Pediatr 1981;99:496-8.

Correspondence to $\mathrm{Dr}$ B A M Smith, Nether Edge Hospital, Osborne Road, Sheffield S11 9EL.

Received 7 March 1984

An article by Lucas et al on preterm formula feeds appears on pp 722-30 of this issue.

\title{
Hypergonadotropic hypogonadism in two sisters with galactosaemia
}

\author{
H P SCHWARZ, H MOSER, J SCHILD, AND K ZUPPINGER \\ Department of Paediatrics, Inselspital, Bern, Switzerland
}

SUMMARY Two sisters with transferase deficiency galactosaemia presented with hypergonadotropic hypogonadism. In the younger girl galactosaemia was documented first at 9 months of age, although she had never been exposed to exogenous galactose in utero or after birth.

Galactosaemia due to deficiency of galactose-1phosphate uridyl transferase (transferase deficiency galactosaemia) is characterised by a well known toxicity syndrome. Dietary restriction of galactose may prevent or reverse most of the symptoms. Only recently has ovarian failure been recognised as a complication of this metabolic disorder ${ }^{12}$ and we are following two sisters who presented with hypergonadotropic hypogonadism at a very young age.

\section{Case reports}

Patient 1. The older of the two girls was born at term by caesarean section to a 23 year old gravida I, para 0 . Her birthweight was $3220 \mathrm{~g}$. She was breast fed but started to vomit and when admitted to hospital at age 9 days was moderately dehydrated and jaundiced. Total bilirubin was $262 \mu \mathrm{mol} / \mathrm{l}$, plasma glucose $3 \cdot 1 \mathrm{mmol} / \mathrm{l}$, serum glutamic oxaloacetic transaminase $123 \mathrm{IU} / \mathrm{l}$, serum glutamic pyruvic transaminase $136 \mathrm{IU} / \mathrm{l}$, alkaline phosphatase 527
IU/l (normal 22 to 98 ), prothrombin time 5\%, plasma galactose $1.4 \mathrm{mmol} / \mathrm{l}(25.4 \mathrm{mg} / \mathrm{dl})$, and erythrocyte galactose-1-phosphate $4.8 \mathrm{mmol} / \mathrm{l}(125$ $\mathrm{mg} / \mathrm{dl}$ ). Generalised aminoaciduria was present. She was given intravenous glucose and one day later was started on a lactose free soy based formula. Galactosaemia was confirmed by a practically absent transferase activity of $0.007 \mu \mathrm{mol} / \mathrm{min} / \mathrm{g}$ haemoglobin ( $1.4 \%$ of normal). After 8 days of treatment her erythrocyte galactose-1-phosphate concentration had dropped to $1.9 \mathrm{mmol} / 1$ but this was still greatly raised five weeks later $(542 \mu \mathrm{mol} / \mathrm{l})$. Subsequent galactose-1-phosphate concentrations, determined three monthly, were between 0 and $235 \mu \mathrm{mol} / \mathrm{l}$. At 2 years of age her IQ (Brunet-Lézine) was 94. Liver enzymes were normal but her basal follicle stimulating hormone concentration was raised (Table); sex chromatin was normal. At $3 \frac{1 / 2}{2}$ years of age a luteinising hormone releasing hormone test $(100 \mu \mathrm{g}$ iv) showed particularly high basal and peak follicle stimulating hormone concentrations as well as a raised peak luteinising hormone concentration. She is now 4 years old and her height, weight, and head circumference are within normal limits. There are no cataracts on slit lamp examination but psychological testing has shown an IQ (Kramer) of 75 with substantial deficits in expressive speech and articulation.

Heterozygosity for galactosaemia was proved in both parents by quantitative measurement of trans- 
782 Schwarz, Moser, Schild, and Zuppinger

Table Gonadotrophin and oestradiol concentrations in the two patients

\begin{tabular}{|c|c|c|c|c|c|c|}
\hline \multirow[t]{2}{*}{ Case No } & \multirow[t]{2}{*}{ Age (years) } & \multicolumn{2}{|l|}{$F S H(I U / l)^{*}$} & \multicolumn{2}{|l|}{$L H(I U / l)^{*}$} & \multirow{2}{*}{$\begin{array}{l}\text { Oestradiol (pmolll) } \\
\text { (normal }<40)\end{array}$} \\
\hline & & $\begin{array}{l}\text { Basal } \\
\text { (normal }<10)\end{array}$ & Peak & $\begin{array}{l}\text { Basal } \\
\text { (normal }<6 \text { ) }\end{array}$ & Peak & \\
\hline \multirow[t]{4}{*}{1} & 2 & 18 & & 4 & & \\
\hline & $211 / 12$ & 29 & & 7 & & \\
\hline & $36 / 12$ & 16 & 54 & 6 & 29 & 22 \\
\hline & 4 & 16 & & 4 & & \\
\hline \multirow[t]{2}{*}{2} & $9 / 12$ & 18 & 63 & 7 & 48 & \\
\hline & $14 / 12$ & 14 & 71 & 5 & 67 & 43 \\
\hline
\end{tabular}

FSH=follicle stimulating hormone: LH=luteinising hormone.

Gonadotrophin were determined by a commercial radioimmunoassay (Byk-Mallinckrodt) using MRC 69/104 as reference standard for FSH and MRC 68/40 for LH.

ferase activity and electrophoretic determination of phenotypes. The mother became pregnant again when her first child was $1 \frac{1}{2}$ years old. Even before this pregnancy she had observed a galactose restricted diet which she rigorously adhered to until she gave birth again.

Patient 2. This girl was also born by caesarean section and weighed $3450 \mathrm{~g}$. She never received lactose and was placed on a soy based formula from the first day of life. Transferase deficiency was confirmed with an activity of $0.009 \mu \mathrm{mol} / \mathrm{min} / \mathrm{g}$ haemoglobin. When first seen in our outpatient clinic at 3 months of age she was a healthy and normally developed infant. Her transaminase concentrations were slightly raised (serum glutamic oxaloacetic transaminase 46 and serum glutamic pyruvic transaminase $62 \mathrm{IU} / \mathrm{l})$, but later became normal. Erythrocyte galactose-1-phosphate was 146 $\mu \mathrm{mol} / \mathrm{l}$ and has never exceeded that value at regular follow up. Basal and luteinising hormone releasing hormone stimulated gonadotrophin concentrations were raised at 9 months of age and this finding was confirmed 7 months later (Table). Sex chromatin was positive. At present she is 1 year 10 months old and her height and weight are between the 10th and 25 th centile. Psychological testing has suggested slight retardation with IQ (Brunet-Lézine) of 87.

\section{Discussion}

The two siblings with transferase deficiency galactosaemia presented with primary hypogonadism documented by several substantially raised basal serum follicle stimulating hormone concentrations with long lasting and excessive increases in follicle stimulating and luteinising hormone after luteinising hormone releasing hormone stimulation. The older girl was treated with a galactose restricted diet from day 9 of life with rapid clinical improvement. The younger girl has been treated by dietary exclusion of galactose, practically since conception.

Hypergonadotropic hypogonadism with primary or premature ovarian failure was present in 12 of 18 adult galactosaemic patients described by Kaufman et al. ${ }^{1}$ No ovarian tissue could be found in three of their patients and although one patient had had normal appearing gonads at age 7 years, streak gonads were found on laparoscopy 10 years later. Dietary treatment had been instituted much later on average in the patients with hypogonadism than in those with normal ovarian function (61 days $v 22$ days). Steinmann $e t \mathrm{al}^{2}$ in a series of 15 galactosaemic patients reported a girl aged 13 years 7 months with normal female karyotype, streak gonads, and primary ovarian failure who had never been exposed to galactose either in utero or after birth. The fact that not all galactosaemic complications may be prevented by early dietary intervention has been recognised for some time. In the earlier study restriction of dietary galactose had been carried out in 11 pregnancies resulting in transferase deficient infants. ${ }^{3}$ One child had cataracts at birth; all children had noticeably raised erythrocyte galactose-1-phosphate concentrations of 150 to $631 \mu \mathrm{mol} / \mathrm{l}$.

Certainly compliance with dietary galactose restriction in a heterozygote mother is difficult to monitor, however, even if dietary indiscretion has occurred, plasma galactose concentrations would not be expected to be particularly high. After intravenous administration of galactose to adult heterozygotes, plasma disappearance rate was not different from that of normal subjects (J Bircher, personal communication). Nonetheless, even low maternal plasma galactose concentrations may be detrimental to the fetus. Galactosaemia in utero with an erythrocyte galactose-1-phosphate concentration of $990 \mu \mathrm{mol} / \mathrm{l}$, high liver concentrations of galactose, galactose-1-phosphate and galactitol, as 
well as galactitol concentrations in amniotic fluid about 15 times above normal have been well documented in early second trimester fetuses. ${ }^{4}$ To our knowledge, galactose and its metabolites have not been measured in gonadal tissue so far. A striking reduction in the number of small oocytes was found in the offspring of rats fed a $50 \%$ galactose diet in the first two thirds of pregnancy. ${ }^{5}$

Thus, prenatal exposure to galactose or its metabolites may be a cause of premature ovarian failure in human galactosaemia. Whether the toxic agent is of maternal or fetal origin remains to be established. There is good evidence that transferase deficient infants can synthesise galactose-1phosphate from glucose via the epimerase and pyrophosphorylase pathway which may lead to self intoxication. ${ }^{6}$ Therefore, strict avoidance of galactose in some high risk pregnancies may not be sufficient for prevention of gonadal damage in the galactosaemic offspring. Familial expression of galactosaemia may differ as not all homozygous women have ovarian failure ${ }^{1}$ and correlation between initiation of treatment and hypogonadism may be poor, ${ }^{2}$ (this report). Clearly more detailed and carefully planned studies are necessary to elucidate these new problems in this otherwise well known disease.

\section{References \\ ${ }^{1}$ Kaufman FR, Kogut MD, Donnell GN, Goebelsmann U, March C, Koch R. Hypergonadotropic hypogonadism in female patients with galactosemia. $N$ Engl J Med 1981;304:994-8. \\ 2 Steinmann B, Gitzelmann R, Zachmann M. Hypogonadism and galactosemia. $N$ Engl J Med 1981;305:464-5. \\ ${ }^{3}$ Donnell GN, Koch R, Bergren WR. Observation on results of management of galactosemic patients. In: Hsia DYY, ed. Galactosemia. Springfield, Illinois: Charles C Thomas, 1969:247-68. \\ ${ }^{4}$ Allen JT, Gillett M, Holton JB, King GS, Pettit BR. Evidence of galactosaemia in utero. Lancet 1980;i:603. \\ ${ }^{5}$ Chen YT, Mattison DR, Feigenbaum L, Fukui H, Schul- man JD. Reduction of oocyte number following prenatal exposure to a diet high in galactose. Science 1981;214:1145-7. \\ ${ }^{6}$ Gitzelmann R, Hansen RG. Galactose biogenesis and disposal in galactosemics. Biochim Biophys Acta 1974;372:374-8.}

Correspondence to Dr H P Schwarz, Universitäts-Kinderklinik, Inselspital, CH-3010 Bern, Switzerland.

Received 28 February 1984

\title{
Familial persistent pulmonary hypertension
}

\author{
I SHOHET, B REICHMAN, G SCHIBI, AND M BRISH \\ Department of Neonatology, Chaim Sheba Medical Center, Tel Hashomer and Department of Paediatrics, \\ Tel Aviv University, Israel
}

SUMMARY We report three siblings who presented with a clinical picture of persistent pulmonary hypertension of newborn and died between 4 and 15 days of age. Pulmonary artery pressure in all was above systemic values, with a right to left shunt via either the foramen ovale or ductus arteriosus, or both. Histology of the pulmonary vascular bed showed extension of muscle into small arteries which are normally non-muscular.

The term persistent pulmonary hypertension of newborn refers to a condition in which pulmonary artery hypertension prevents the successful transition from the fetal to adult circulation. ${ }^{1}$ The neonate continues to have raised pulmonary vascular resistance, with pulmonary artery pressure higher than systemic values. Persistent right to left shunting through the foramen ovale and ductus arteriosus results in hypoxaemia, acidosis, and respiratory distress. Although most cases are associated with well defined clinical entities, ${ }^{23}$ primary hypertrophy of the muscular layers of the pulmonary arterioles has been described. ${ }^{4}$

We report three siblings with persistent pulmonary hypertension of newborn associated with abnormal muscularisation of the intra-acinar pulmonary arteries. To our knowledge, this is the first report of familial primary pulmonary hypertension of the newborn, and the occurrence in three siblings suggests a recessively inherited genetic trait.

\section{Case reports}

Two boys and one girl from the same family with clinical and pathological features of persistent pulmonary hypertension of newborn are described. The infants were born to healthy parents of Tunisian origin who are first degree cousins. Two additional siblings born after the death of the first two sick infants are normal. No history of unexpected fetal or neonatal deaths in the extended family was recorded. The mother received no medication during 